\title{
SUPPLEMENTATION WITH 2:1 RATIO OF N-6:N-3 POLYUNSATURATED FATTY ACID IMPROVES LIVER STEATOSIS AND SERUM CYTOKINE LEVELS IN YOUNG OBESE BALINESE WOMEN: A RANDOMIZED CLINICAL TRIAL
}

\author{
WAYAN WETA I ${ }^{1}$, MAHADEWA TJOKORDA GB ${ }^{2 *}$, WAYAN P SUTIRTAYASA ${ }^{2}$, ANAK A NGURAH SUBAWA ${ }^{3}$, \\ SAFARINA G MALIK ${ }^{4}$, PUTU EKA WIDYADHARMA I
}

\begin{abstract}
${ }^{1}$ Department of Community and Preventive Medicine, Clinical Nutrition, Faculty of Medicine, Udayana University, Sanglah Hospital, Denpasar, Bali, Indonesia. ${ }^{2}$ Faculty of Medicine, Udayana University, Denpasar, Bali, Indonesia. ${ }^{3}$ Department of Clinical Pathology, Faculty of Medicine, Sanglah Hospital, Denpasar, Bali, Indonesia. ${ }^{4}$ Eijkman Institute for Molecular Biology, Ministry of Research Technology and Higher Education, Republic of Indonesia, Jakarta, Indonesia. Email: tjokmahadewa@hotmail.com
\end{abstract}

Received: 02 August 2017, Revised and Accepted: 15 August 2017

\section{ABSTRACT}

Objectives: In addition to the rise in obesity prevalence globally, morbidity due to nonalcoholic fatty liver disease is increasing. Primary modalities for preventing and managing this problem include dietary modification and improved physical activities. A daily diet with a low n-6:n-3 polyunsaturated fatty acid (PUFA) ratio is suspected to contribute to ameliorating liver steatosis (LS). The present study was conducted to elucidate the effects of an n-6:n-3 PUFA ratio of 2:1 in alleviating LS.

Methods: Twenty-four young obese women with LS were recruited from Denpasar, Bali, Indonesia. They were randomly allocated to an intervention or control group. Both groups were given linoleic acid: $\alpha$-linolenic acid at ratios of 2035:970 and 240:100 g, respectively, for 12 weeks. Baseline and end-line data were obtained. All patients were advised to maintain their daily energy intake no more than 1500 kcal and to perform structured physical exercises once a week.

Results: The intervention significantly decreased the body fat (body mass index, $\mathrm{p}=0.040$; triglyceride, $\mathrm{p}=0.008$ ) and serum tumor necrosis factor- $\alpha$ (TNF- $\alpha$ ) levels ( $\mathrm{p}=0.002)$ and increased serum interleukin-10 (IL-10) levels ( $\mathrm{p}=0.004)$. The severity of LS was reduced through the intervention (odds ratio $=0.064 ; 95 \%$ confidence interval $=0.013-0.310 ; \mathrm{p}=0.001$ ).

Conclusion: An increased intake of 2:1 n-6:n-3 PUFA ratio alleviated LS, decreased body fat composition and serum TNF- $\alpha$ levels, and increased serum IL-10 levels.

Keywords: Young obese women, 2:1 n-6:n-3 Polyunsaturated fatty acid ratio, Cytokines, Liver steatosis.

(c) 2017 The Authors. Published by Innovare Academic Sciences Pvt Ltd. This is an open access article under the CC BY license (http://creativecommons. org/licenses/by/4. 0/) DOI: http://dx.doi.org/10.22159/ajpcr.2017.v10i12.20851

\section{INTRODUCTION}

Nonalcoholic fatty liver disease (NAFLD), or liver steatosis (LS), is an emerging global health problem. It has been associated with an increase in morbidity in western populations and is currently also affecting Southeast Asian populations. NAFLD is an accumulation of fat in the liver of nonalcoholic individuals. This accumulation of fat, particularly intrahepatic triglycerides (TGs), occurs due to several mechanisms, i.e, increased influx of free fatty acids into the liver, increased fat synthesis, decreased TG export through very low-density lipoprotein (VLDL), and reduced $\beta$-oxidation [1-3]. Fat accumulation indicates that hepatic fatty acid uptake from the plasma and de novo fatty acid synthesis occur at a faster rate than do $\beta$-oxidation and export [3]. NAFLD occurs as two entities, i.e, non-alcoholic fatty liver (NAFL) and succeeded by non-alcoholic steatohepatitis (NASH) in the later stage. NAFL is defined as hepatic steatosis without inflammation, whereas NASH is steatosis accompanied by inflammation [3]. NAFLD is the most common liver disorder and is the leading cause of hepatocyte injury and fibrosis. NAFLD is also associated with chronic liver diseases such as cirrhosis [4-8].

The two-hit theory explains the development and progression of NAFLD. The first hit initiates LS, and the second hit stimulates inflammatory processes. These two conditions may result in hepatocyte injury and fibrosis $[4,5]$. NAFLD is asymptomatic, undetectable, and progressive. Except for individuals who consume more than $20 \mathrm{~g}$ of ethanol daily, imaging studies or liver biopsies can be used to diagnose NAFLD. Liver biopsy is the definitive method for diagnosing NAFLD, yet this method is invasive, traumatic, and expensive. Ultrasound (US) imaging is an alternative method for diagnosing suspected NAFLD cases. This method is relatively safe and inexpensive, with good sensitivity and specificity [9].

Approximately $20-35 \%$ of the global population has LS, and $10 \%$ of cases are more severe than NASH. The prevalence of LS is higher among patients with obesity and type 2 diabetes (70-80\%), and as many as $25-$ $70 \%$ of these patients eventually develop chronic liver diseases such as NASH and fibrosis [6-8]. Obesity, a high-fat diet, a genetic predisposition, and microbiota have been identified as risk factors for NAFL [4-8]. In obese patients associated chronic inflammatory states, the adipose tissue releases more pro-inflammatory cytokines such as tumor necrosis factor- $\alpha$ (TNF- $\alpha$ ) and interleukin (IL)-6, whereas the release of IL-10 is decreased. Moreover, the levels of pro-inflammatory cytokines, such as TNF- $\alpha$ and IL-16, produced by the liver and adipose tissue are elevated during the activation of nuclear factor kappa B. TNF- $\alpha$ involves in inflammatory and metabolic alterations nearly stage of liver injury, leading to increased cytokines synthesis, which in turn induces cell migration, initiate fibrotic processes, and influence the progression of NAFL to NASH [4-8]. By contrast, IL-10 inhibits the synthesis of pro-inflammatory cytokines such as interferon- $\gamma$, IL-2, IL-3, and TNF- $\alpha$. These cytokines are mainly secreted by T regulatory cells. Obesity is associated with decreased IL10 concentrations [10]. Research has shown that an imbalance between 
pro-inflammatory (TNF- $\alpha$ ) and anti-inflammatory (IL-10) cytokine levels are associated with a high n-6:n-3 ratio in the cell membranes of obese patients. The amounts of $n-3$ polyunsaturated fatty acid (PUFA) $(\alpha$-linolenic acid [ALA]) and long-chain (LC)-PUFA (eicosapentaenoic acid [EPA] and docosahexaenoic acid [DHA]) in obese patients were shown to be, respectively, $30 \%$ and $35 \%$ lower than those in normal-weight patients. By contrast, n-6 PUFA (linoleic acid [LA]) and LC-PUFA (arachidonic acid $[\mathrm{AA}])$ levels were shown to be relatively higher in obese patients than in non-obese patients [11]. Another study demonstrated that an increased n-6:n-3 PUFA ratio induces steatosis and inflammation, which leads to NAFLD [12]. Nutritional modification, such as increasing the n-3 PUFA proportion in the diet, can reduce the risk of obesity, inflammation, and oxidative stress and prevent the development of LS [13]. Few types of oil, such as canola oil, contain high n-3 PUFA (ALA) concentration. ALA is desaturated and elongated to EPA and DHA. n-3 LC-PUFA reduces lipogenic processes in the liver by inhibiting the sterol regulatory element binding protein-1c (SREBP1c) and carbohydrate-responsive elementbinding protein. Furthermore, it also stimulates paroxysmal proliferatoractivated receptor (PPAR)- $\alpha$ and activates a protein kinase (AMPK) to increase the $\beta$-oxidation of hepatic lipids. It also increases lipid oxidation in adipose and skeletal tissues through AMPK [14]. The present study was conducted to elucidate the effects of n-6:n3 PUFA supplementation at a ratio of 2:1 for alleviating LS and improving serum TNF- $\alpha$ and IL-10 levels in young Balinese obese women.

\section{METHODS}

\section{Research design, participants, and intervention}

This study was a randomized trial with a double-blind control groupbased pre- and post-test design [15]. It involved young obese women (age, 18-25 years) in Denpasar. They were recruited between May and September 2013 (clinical trial ID ACTRN12615000757516).

This study is part of a larger research project investigating the effects of low-ratio n-6:n-3 PUFA supplementation for alleviating obesity and its comorbidities in young obese women in Bali. Sixty-six young obese women (body mass index [BMI] $\geq 25 \mathrm{~kg} / \mathrm{m}^{2}$ ) were screened for LS through US imaging (Logiq 500, GE, Solingen, Germany); 26 (39.4\%) of them were found to have LS and were randomly enrolled in this study. They were allocated to either intervention or control group (13 patients in each group). Informed consent was obtained from all patients before enrolment. The study protocol was approved by the Research Ethics Committee of Udayana University, Sanglah Hospital (Ethical Clearance No. 787/UN.14.2/Litbang/2012, 17 September 2012)

The intervention group received supplementation with $30 \mathrm{~mL}$ of emulsion containing $10 \mathrm{~g}$ of canola oil $(952 \mathrm{mg}$ of saturated fatty acid [SFA], $6072 \mathrm{mg}$ of monounsaturated fatty acid [MUFA], $2035 \mathrm{mg}$ of LA, and 970 mg of ALA; n-6:n-3 PUFA ratio of 2:1) [16,17], and the control group received supplementation with $30 \mathrm{~mL}$ of placebo containing $2 \mathrm{~g}$ of palm oil ( $660 \mathrm{mg}$ of SFA, $1000 \mathrm{mg}$ of MUFA, $240 \mathrm{mg}$ of LA, and 100 mg of ALA; n-6:n-3 PUFA ratio of 2:1) $[17,18]$. Supplementation was provided daily for 12 weeks (June 2013-September 2013). Furthermore, the participants were advised to restrict their daily energy intake to $<1500 \mathrm{kcal}$. To ensure compliance, weekly meetings (every Sunday) were organized. During these meetings, they were advised to participate in aerobic exercises for $1 \mathrm{hr}$ under the supervision of a gym instructor. They were given $250 \mathrm{~mL}$ of emulsions per week, and any complaints or adverse effects related to the supplementation were monitored. To ensure that, the previous week's dose was consumed as instructed, and the volume of the remaining emulsion in the used bottles was recorded.

During this period, two participants from the intervention group were lost to follow-up. In total, 24 patients (11 in the intervention group and 13 in the control group) completed the study protocol and were included in the analysis.

\section{Data collection}

All research variables were assessed on the first day of week 1 (baseline data) and last day of week 12 (end-line data). Energy intake was assessed using a semi-quantitative food frequency questionnaire. Body weight (BW) was measured using a digital scale (Omron HBF-362 model, Kyoto, Japan), with a precision of $0.1 \mathrm{~kg}$, and body height (BH) was measured using a stature meter, with an accuracy of $0.1 \mathrm{~cm}$. BMI was calculated as BW $(\mathrm{kg}) / \mathrm{BH}(\mathrm{m})^{2}$. Serum TG and gamma glutamyl transferase (GGT) levels were measured using the colorimetric method (Cobas 6000-Roche Diagnostic, Mannheim, Germany), with precisions of $1 \mathrm{mg} / \mathrm{dL}$ and $1 \mu \mathrm{g} / \mathrm{L}$, respectively.

Serum TNF- $\alpha$ and IL-10 levels were assessed using an ELISA kit (Boster Biological Technology Ltd, Pleasanton, CA, USA), according to the manufacturer's instructions. The results were examined with an ELISA reader $(\mathrm{pg} / \mathrm{mL})$.

LS was assessed through US imaging, the results of which were independently interpreted by three radiologists. The final interpretation was determined through majority decision. The defining criteria for LS are as follows: (1) Normal liver (absence of steatosis and other liver disorders), (2) mild steatosis (appearance of a slightly bright liver parenchymal or hepatorenal echo contrast without intrahepatic vascular disorder), (3) moderate steatosis (more colored liver parenchymal or hepatorenal appearance in more areas without intrahepatic vascular disease), and (4) severe steatosis (diffused and brighter liver appearance with blunting intrahepatic vascular disorder) $[19,20]$.

\section{Statistical analyses}

Statistical analyses were performed using Stata 12.1 (Stata Corp, College Station, TX, USA). A generalized linear model was employed to explore the relationships of variables within and between the groups. Repeated ordered logistic regression was used to assess the ORs between severe and less severe LS. The significance level for all statistical analyses was p $<0.05$ (95\% confidence intervals [CI]) [21] (Fig. 1).

\section{RESULTS}

All participants were Balinese, with the mean age of $20.8 \pm 1.7$ years (range, 18-24 years). Most participants were students of Udayana University (87.5\%). All of the baseline characteristics, namely, age, occupation, selected nutrients intake (except cholesterol), BMI, waist circumference, TG, and GGT were comparable between the intervention and the control group. However, two nutrient intakes, namely, cholesterol and fiber were in extreme values. There was a high cholesterol intake in the intervention group (354 mg) compared to the control group $(240 \mathrm{mg})(\mathrm{p}=0.033)$. In contrary for the fiber consumption, both the intervention and the control group had a low-fiber intake (7.86 g and $12.8 \mathrm{~g}$; $\mathrm{p}=0.135$ respectively), less than Indonesian RDA ( $32 \mathrm{~g}$ ) (Table 1). The sources of fat intake were mainly palm oil, chicken, and red meat (Table 2).

The reduced total energy intake between the baseline and end-line did not differ in the intervention and control groups $(\mathrm{p}=0.053$ and $\mathrm{p}=0.551$, respectively) and remained at $>1500 \mathrm{kcal}$ in both the groups. Moreover, no significant difference was observed in the changes in total energy intake between the two groups ( $\mathrm{p}=0.257$; Table 3$)$.

In the intervention group, a significant reduction in the BMI and TG levels between the baseline and end-line was noted $(p=0.040$ and $\mathrm{p}=0.008$, respectively), but this finding was not observed in the control group. The BMI and TG levels did not differ between the two groups (BMI, $p=0.150 ; T G, p=0.433$ ). A greater reduction in serum GGT levels occurred in the intervention group than in the control group, but this difference was not statistically significant.

Serum TNF- $\alpha$ and IL-10 concentrations were not normally distributed; therefore, $\log$ transformation was performed. In the intervention group, the concentration of serum TNF- $\alpha$ decreased from baseline and endline $(p=0.002)$, whereas the IL- 10 concentration increased $(p=0.004)$. By contrast, only the IL-10 serum concentration increased $(\mathrm{p}=0.0038$; Table 3) in the control group. 
Table 1: Baseline characteristics of participants stratified by group

\begin{tabular}{|c|c|c|c|}
\hline \multirow[t]{2}{*}{ Parameters } & \multicolumn{2}{|c|}{ Group (mean $\pm S E)$} & \multirow[t]{2}{*}{$\mathbf{p}$} \\
\hline & $\begin{array}{l}\text { Intervention } \\
(n=11)\end{array}$ & $\begin{array}{l}\text { Control } \\
(n=13)\end{array}$ & \\
\hline Age (years) & $21.2 \pm 1.8$ & $20.5 \pm 1.7$ & 0.338 \\
\hline \multicolumn{4}{|l|}{ Occupation } \\
\hline \multicolumn{4}{|l|}{$\mathrm{F}(\%)$} \\
\hline Student & $10(90.9)$ & $11(84.6)$ & 0.589 \\
\hline Officer staff & $1(9.1)$ & $1(7.7)$ & \\
\hline Unemployment & - & $1(7.7)$ & \\
\hline \multicolumn{4}{|c|}{ Specified nutrients intake } \\
\hline Energy (kcal) & $2187 \pm 203$ & $1714 \pm 170$ & 0.848 \\
\hline Fat $(\mathrm{g})$ & $82.0 \pm 9.11$ & $67.9 \pm 13.5$ & 0.976 \\
\hline PUFA (g) & $19.1 \pm 3.09$ & $15.8 \pm 3.36$ & 0.978 \\
\hline Cholesterol (mg) & $354 \pm 48.1$ & $240 \pm 40.3$ & 0.033 \\
\hline Fiber (g) & $7.86 \pm 0.91$ & $12.8 \pm 3.36$ & 0.135 \\
\hline BMI $\left(\mathrm{kg} / \mathrm{m}^{2}\right)$ & $33.8 \pm 2.32$ & $34.1 \pm 1.33$ & 0.916 \\
\hline Triglyceride (mg/dl) & $157 \pm 16.5$ & $130 \pm 22.5$ & 0.580 \\
\hline GGT $(\mu \mathrm{g} / \mathrm{l})$ & $25.8 \pm 2.94$ & $25.2 \pm 2.88$ & 0.351 \\
\hline
\end{tabular}

PUFA: Polyunsaturated fatty acids, BMI: Body mass index, GGT: Gamma glutamyl transferase, SE: Standard error
Compared with the control group, a significant improvement was noted in the LS condition of the intervention group after the 12-week intervention, with an OR of 0.064 (95\% CI 0.013-0.310, p=0.001; Table 3).

\section{DISCUSSION}

Following the present findings, most studies - both in animals and humans -have documented the benefits of n-3 PUFA supplementation for treating NAFLD by improving the cytokine profiles and reducing inflammation and oxidative stress.

In a recent animal model study, Konuma et al. used plant oils as a source of n-3 PUFA demonstrated that a low n-6:n-3 PUFA ratio improved serum lipid metabolism, inflammatory cytokines levels, oxidative stress, and endothelial function. They found that EPA effectively prevented the development and progression of NASH and ameliorated hepatic steatosis in mice [22]. Heerwagen et al. revealed that a highfat diet significantly increased the n-3:n-6 PUFA ratio and reduced maternal obesity-associated inflammation in Fat-1 transgenic mice. In that study, wild-type mice fed with a high-fat diet exhibited a high serum concentration of 12 pro-inflammatory cytokines $(\mathrm{p}<0.05)$, but no such increase was observed in the transgenic mice [23]. Depner et al. reported that among n-3 LC-PUFAs, DHA was more effective than

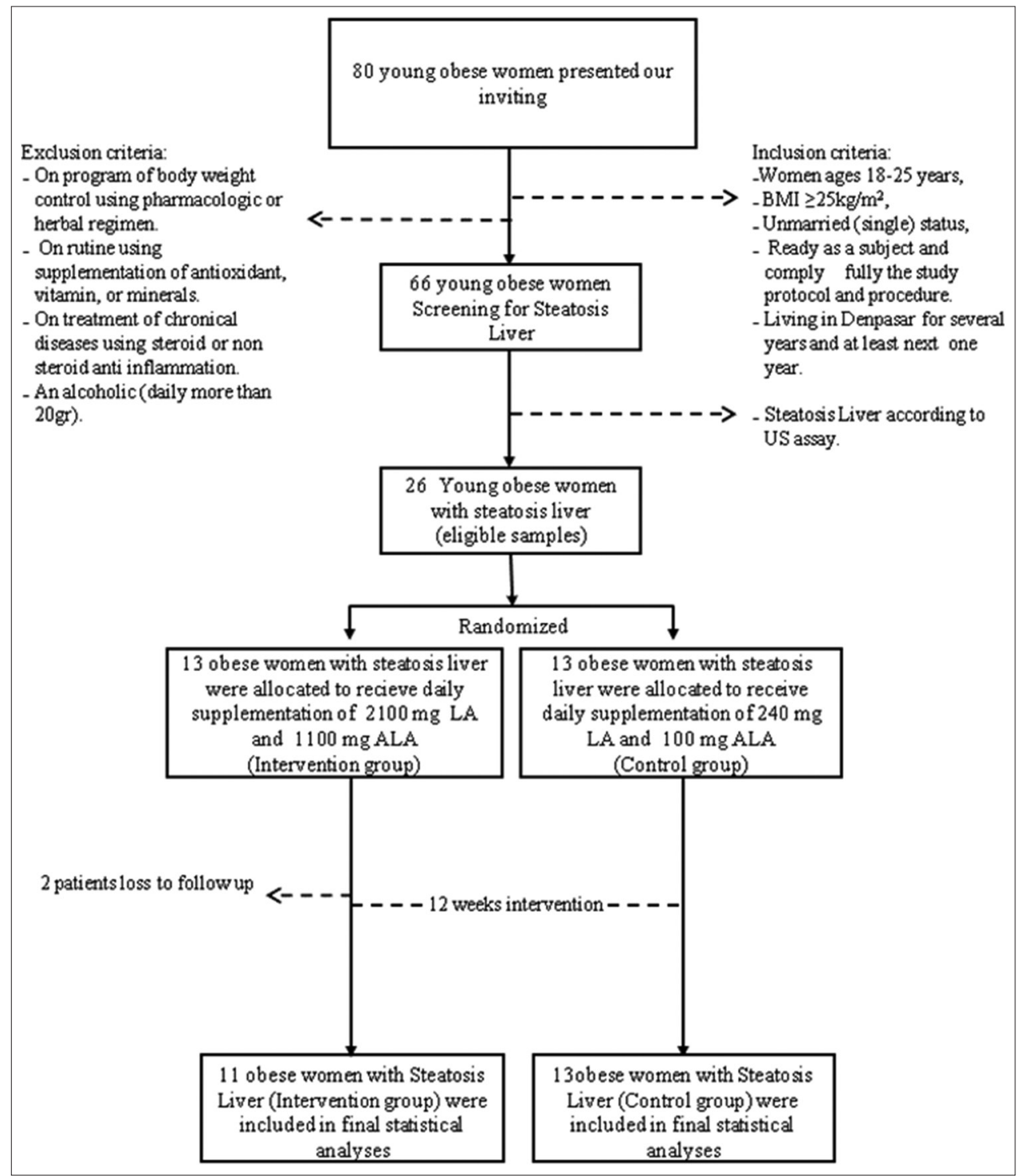

Fig. 1: Sequence of participants recruitment and pathways of research procedure 
EPA in attenuating inflammation, oxidative stress, fibrosis, and hepatic damage [24]. Lionetti et al. described that EPA effectively minimized saturated fat-induced insulin resistance in mice and decreased leptin alleviated LS and improved secondary outcomes, such as BMI, TG and alanine transaminase levels, and homeostasis model assessment of insulin resistance values in both groups when compared to the control group [25]. A systematic review and meta-analysis of five randomized controlled trials (nine studies) in which n-3 LC-PUFA supplementation was provided for 8 weeks to 12 months to 355 adults with NAFLD demonstrated that n-3 LC-PUFA was beneficial in reducing liver fat $(\mathrm{p}<0.001)$ and aspartate aminotransferase $(\mathrm{p}=0.02)$ but not alanine aminotransferase activity [26]. Another study reported that a reduction in the n-6:n-3 PUFA ratio $(3: 1)$ in the diet resulted in decreased plasma

Table 2: Baseline fatty food consumption patterns (time/day) of the participants $(n=24)$

\begin{tabular}{lll}
\hline Fat sources & F (\%) & Mean \pm SE \\
\hline Animal & $12(50.0)$ & \\
Beef & $16(66.7)$ & $0.25 \pm 0.09$ \\
Pork & $8(33.4)$ & $0.19 \pm 0.08$ \\
Lamb & $22(91.7)$ & $0.27 \pm 0.09$ \\
Chicken & $10(41.7)$ & $1.20 \pm 0.19$ \\
Full cream milk & $14(58.3)$ & $0.25 \pm 0.72$ \\
Cheese & $9(37.5)$ & $0.27 \pm 0.08$ \\
Butter/margarine & $19(79.2)$ & $0.18 \pm 0.09$ \\
Fast food/street food & $19(79.2)$ & \\
$\quad$ Fried chicken & $4(16.7)$ & $0.45 \pm 0.35$ \\
$\quad$ Meatball (bakso) & $19(79.2)$ & \\
Plant & $3(12.5)$ & $2.07 \pm 0.07$ \\
Coconut oil & $14(58.3)$ & $1.35 \pm 0.86$ \\
Palm oil & & $0.79 \pm 0.18$ \\
$\quad$ Olive oil &
\end{tabular}

TG levels in mRNA expression in vivo and in vitro. A decline in the circulating levels of leptin may reduce the white adipose tissue mass and eventually reduce the BW and degree of systemic inflammation in rats. In another study [27], marine n-3 PUFAs were found to have an anti adipogenic effect during obesity development in mice. The study showed that it inhibited the growth of fat cells through both hypertrophy and hyperplasia processes. In human studies, Nobili et al. have demonstrated that supplementation with two doses of $250 \mathrm{mg}$ and $500 \mathrm{mg}$ of DHA daily for 2 years in children with NAFLD patients aged 45-75 years [28-30]

In the present study, the use of plant (canola) oil with an n-6 (LA):n-3 (ALA) PUFA ratio of 2:1 appeared to improve the composition of n-6 (AA) and n-3 (EPA and DHA) LC-PUFAs in the phospholipid cell membrane. ALA desaturated and elongated in animal and human bodies to form LC PUFAs (EPA, DPA, and DHA). By contrast, LA desaturated and elongated to form $\gamma$-linolenic acid and dihomo- $\gamma-$ linolenic acid (DGLA), and DGLA desaturated to form n-6 LC-PUFA (AA) [31]. DGLA is a n-6 PUFA that produces anti-inflammatory eicosanoids, the prostaglandin 1 series (PG-1), which differ from the pro-inflammatory prostaglandin 2 series (PG-2) released by AA. In addition, ALA also desaturated and elongated to form EPA. Increased EPA levels potentially inhibit the $\delta$ - 5 desaturase enzyme, which is required by DGLA to form AA [32]. Thus, this plant oil exerts its beneficial effects by increasing EPA levels and DLGA to produce PG-3 and PG-1 while inhibiting the AA formation that releases PG-2. Furthermore, a low n-6:n-3 PUFA ratio controls the inflammatory state by inducing the release of anti-inflammatory cytokines and inhibiting the release of pro-inflammatory cytokines.

In addition, Burdge et al. analyzed the EPA and DHA obtained from the desaturation and elongation of ALA. They observed that on average, as much as $36 \%$ of ALA was converted to n-3 LC-PUFA (21\% EPA, $6 \%$ DPA, and $9 \%$ DHA) in young obese women. ALA conversion to n-3 LC-PUFA

Table 3: Relationship of intervention with energy intake, body lipid composition, cytokine levels, and liver steatosis $(n=24)$

\begin{tabular}{|c|c|c|c|c|}
\hline \multirow[t]{2}{*}{ Parameter group } & \multicolumn{3}{|l|}{ Mean \pm SE } & \multirow[t]{2}{*}{$\mathbf{p}$} \\
\hline & Baseline & Endline & Difference & \\
\hline \multicolumn{5}{|l|}{ Energy intake (kcal) } \\
\hline Intervention ( $\mathrm{n}=11)$ & $2187 \pm 203$ & $1691 \pm 209$ & $-497 \pm 226$ & 0.053 \\
\hline Control (n=13) & $1714 \pm 170$ & $1574 \pm 158$ & $-140 \pm 206$ & 0.511 \\
\hline $\mathrm{p}$ & & & 0.257 & \\
\hline \multicolumn{5}{|l|}{ BMI $\left(\mathrm{kg} / \mathrm{m}^{2}\right)$} \\
\hline Intervention ( $\mathrm{n}=11)$ & $33.8 \pm 2.32$ & $33.0 \pm 2.31$ & $-0.74 \pm 0.31$ & 0.040 \\
\hline Control $(n=13)$ & $34.1 \pm 1.33$ & $34.5 \pm 1.11$ & $0.43 \pm 0.69$ & 0.546 \\
\hline $\mathrm{p}$ & & & 0.150 & \\
\hline \multicolumn{5}{|l|}{ Triglyceride (mg/dl) } \\
\hline Intervention (n=11) & $157.4 \pm 16.5$ & $129.1 \pm 16.2$ & $-28.3 \pm 8.5$ & 0.008 \\
\hline Control $(n=13)$ & $129.9 \pm 22.5$ & $117.9 \pm 11.5$ & $-11.9 \pm 17.3$ & 0.505 \\
\hline $\mathrm{p}$ & & & 0.433 & \\
\hline \multicolumn{5}{|l|}{ GGT $(\mu \mathrm{g} / \mathrm{l})$} \\
\hline Intervention $(\mathrm{n}=11)$ & $25.8 \pm 2.94$ & $21.8 \pm 2.74$ & $-3.97 \pm 2.15$ & 0.074 \\
\hline Control $(n=13)$ & $25.2 \pm 2.88$ & $24.7 \pm 3.24$ & $-0.45 \pm 1.67$ & 0.788 \\
\hline $\mathrm{p}$ & & & 0.202 & \\
\hline \multicolumn{5}{|l|}{ Log. IL10 } \\
\hline Intervention $(\mathrm{n}=11)$ & $0.82 \pm 0.24$ & $1.55 \pm 0.07$ & $0.73 \pm 0.23$ & 0.004 \\
\hline Control $(n=13)$ & $1.31 \pm 0.11$ & $1.54 \pm 0.05$ & $0.23 \pm 0.10$ & 0.038 \\
\hline $\mathrm{p}$ & & & 0.053 & \\
\hline \multicolumn{5}{|l|}{ Log. TNF- $\alpha$} \\
\hline Intervention (n=11) & $1.87 \pm 0.06$ & $1.58 \pm 0.08$ & $-0.29 \pm 0.08$ & 0.002 \\
\hline Control (n=13) & $1.89 \pm 0.08$ & $1.71 \pm 0.13$ & $-0.18 \pm 0.15$ & 0.242 \\
\hline & & & 0.516 & \\
\hline \multicolumn{5}{|c|}{ Liver steatosis $(0 / 1 / 2 / 3)^{\dagger}$} \\
\hline Intervention $(\mathrm{n}=11)$ & $0 / 5 / 3 / 3$ & $5 / 3 / 2 / 1$ & $5 /-2 /-1 /-2$ & 0.064 \\
\hline Control $(n=13)$ & $0 / 6 / 1 / 6$ & $3 / 4 / 3 / 3$ & $3 /-2 / 2 /-3$ & $(0.013-0.31)^{+\dagger}$ \\
\hline $\mathrm{p}$ & & & & 0.001 \\
\hline
\end{tabular}

SE: Standard error of the mean, TNF: Tumor necrosis factor, IL: Interleukin, GGT: Gamma glutamyl transferase. p, analyzed using a general linear model. ${ }^{\dagger}$ Liver steatosis level: 0 , none; 1 , mild; 2 , moderate; 3 , severe. The data are presented as the frequency distribution and analyzed using the ordinal generalized model. ${ }^{+} \mathrm{OR}(95 \% \mathrm{CI}) ; \mathrm{OR}$ of more severe to less severe liver steatosis 
was also reported to be higher among young obese women than among young obese men, probably due to the lower level of lipid $\beta$-oxidation among women [33].

EPA and DHA regulate adiposity through two mechanisms. First, n-3 LC-PUFAs reduce endogenous lipid production by inhibiting the expression and processing of SREBP1c, which stimulates lipogenic gene transcriptions [14,34,35]. Second, n-3 LC-PUFAs are potent PPAR- $\alpha$ activators and PPAR- $\gamma$ inhibitors that upregulate several gene expression pathways involved in the stimulation of fatty acid $\beta$-oxidation [14,35-38]

In the present study, reduced TNF- $\alpha$ and increased IL-10 levels were associated with reduced inflammation in the participants after the 12week intervention. The release of GGT typically increases oxidative stress [39]; however, serum GGT levels were relatively decreased in this study, indicating that oxidative stress was reduced. Furthermore, GGT has been strongly associated with body lipids, particularly visceral fat, which contribute to the progression of NAFLD $[23,24,40]$.

In animals study, other antioxidant nutrients also reported have a positive effect in reducing liver inflammatory and fibrosis. AbdelSttar et al. [41] studied that hesperidin (3,5,7-trihydroxy flavanone7-rhamnoglucoside) and a flavanone glycoside present abundantly in citrus fruits, significantly ameliorated carbon tetrachloride (liver fibrosis inducer) in rats based on its antioxidant, anti-inflammatory, antilipidemic, and anti-fibrotic activities. Ahmed et al. [42] reported grape seeds (Vitis vinifera) extract contains flavonoids, polyphenols, anthocyanins, proanthocyanidins, procyanidins, and the stilbene derivative resveratrol bioactive phytochemicals that possess inhibitory activity on the fat-metabolizing enzymes, pancreatic lipase, and lipoprotein lipase. Vitis Vinifera seed extract has potent therapeutic implication in NASH accompanied with insulin resistance and severe inflammation. Human trials are clearly needed in the future in order to confirm whether or not the combination of those nutrients supplementation with n-6:n-3 PUFA on 2:1 ratio can strengthen the effects of the present study.

Many risk factors, such as unhealthy diet comprising high energy, high saturated fat, and high n-6:n3 PUFA ratio, along with sedentary lifestyle, are associated with obesity and insulin resistance. It facilitates the influx of free fatty acids from the adipose tissue into the liver, hepatic oxidative stress, cytokine production, reduced VLDL secretion, and the growth of the intestinal microbiome [43]. Unhealthy diet and a sedentary lifestyle can alter the stability of the intestinal microbiome composition. This leads to the development of chronic diseases such as obesity and metabolic dysfunction [44]. These factors are associated with the progression of NAFL to NASH.

NAFLD is asymptomatic and undetectable in its early stages, and a definitive pharmacologic regimen has yet to be identified. If NAFLD is neither identified in its early stages nor managed appropriately, the disease will naturally progress to the severe NASH stage, which entails inflammation, fibrosis, and cirrhosis [3]. Non-invasive US imaging is an appropriate first-line method for the early detection of asymptomatic NAFLD [40]. Schwenger et al. [3] recommended that an improvement in diet and increase in physical activity should be the first choice to treat NAFLD, followed by the management of insulin resistance, oxidative stress, and obesity-associated morbidity.

The results of this study suggest that the risk of NAFLD should be monitored among obese patients. Early identification and appropriate management of LS are crucial, particularly among obese patients. An improvement in the quality of life through the modification of daily life behaviors, such as by maintaining a healthy and balanced diet and increasing physical activities, is essential to effectively manage LS. Healthy diets and supplementation with a low n-6:n-3 PUFA ratio are beneficial in alleviating and treating NAFLD, improving the body lipid composition, and controlling inflammation.
We conclude that daily supplementation with an n-6:n-3 PUFA ratio of 2035:970 mg (LA:ALA) for 12 weeks alleviates LS reduces body fat composition and serum TNF- $\alpha$ levels and increases the serum concentration of IL-10 in young obese Balinese women.

\section{ACKNOWLEDGMENTS}

This study was financially supported by the Doctorate Grant Program of Danone Institute Indonesia. The authors are grateful to all the participants. The authors would like to thank Professor Claudio Tiribelli (University of Trieste Liver Research Center), Professor Giorgio Bedogni (University of Modena), and Professor Reggio Emilia (Liver Research Center, Italy) for their expert comments and input. The authors also thank all students, dieticians, and aerobics instructors for their support and contributions to this study.

\section{REFERENCES}

1. Fabbrini E, Sullivan S, Klein S. Obesity and nonalcoholic fatty liver disease: Biochemical, metabolic, and clinical implications. Hepatology 2010;51(2):679-89.

2. Mirza MS. Obesity, visceral fat, and NAFLD: Querying the role of adipokines in the progression of nonalcoholic fatty liver disease. ISRN Gastroenterol 2011;2011:592404

3. Schwenger KJ, Allard JP. Clinical approaches to non-alcoholic fatty liver disease. World J Gastroenterol 2014;20(7):1712-23.

4. Sharma M, Mitnala S, Vishnubhotla RK, Mukherjee R, Reddy DN, Rao PN. The riddle of nonalcoholic fatty liver disease: Progression from nonalcoholic fatty liver to nonalcoholic steatohepatitis. J Clin Exp Hepatol 2015;5(2):147-58.

5. Malaguarnera M, Di Rosa M, Nicoletti F, Malaguarnera L. Molecular mechanism involved in NAFLD progression. J Mol Med 2009;87:679-95.

6. Angulo P. Obesity and nonalcoholic fatty liver disease. Nutr Rev 2007;65:S57-63.

7. de Alwis NM, Day CP. Non-alcoholic fatty liver disease: The mist gradually clears. J Hepatol 2008;48:S104-12.

8. More JB. Non-alcoholic fatty liver disease: The hepatic consequence of obesity and the metabolic syndrome. Conference on 'Overand undernutrition: Challenges and approaches'. Proc Nutr Soc 2010;69:211-20.

9. Obika M, Noguchi H. Diagnosis and evaluation of non alcoholic fatty liver disease. Exp Diabetes Res 2012;2012:145754

10. Jung SH, Park HS, Kim KS, Choi WH, Ahn CW, Kim BT, et al. Effect of weight loss on some serum cytokines in human obesity: Increase in IL-10 after weight loss. J Nutr Biochem 2008;19(6):371-5.

11. Greenberg AS, Obin MS. Obesity and the role of adipose tissue in inflammation and metabolism. Am J Clin Nutr 2006;83(2):461S-5.

12. Tateya S, Kim F, Tamori Y. Recent advances in obesity-induced inflammation and insulin resistance. Front Endocrinol (Lausanne) 2013;4:93

13. Elizondo A, Araya J, Rodrigo R, Signorini C, Sgherri C, Comporti M, et al. Effects of weight loss on liver and erythrocyte polyunsaturated fatty acid pattern and oxidative stress status in obese patients with nonalcoholic fatty liver disease. Biol Res 2008;41(1):59-68.

14. Kalupahana NS, Claycombe KJ, Moustaid-Moussa N. (n-3) Fatty acids alleviate adipose tissue inflammation and insulin resistance: Mechanistic insights. Adv Nutr 2011;2(4):304-16.

15. Pocock SJ. Clinical Trials-A Practical Approach. Chichester: John Wiley and Sons; 2008.

16. USDA. National Nutrient Database for Standard Reference, SR-27. Baltimore: National Agricultural Library; 2011.

17. McDonald BE. Canola oil: Nutritional Properties. Canada: Canola Council of Canada; 2005. Available from: http://www.canola-Council. org/pdf/nutritionalprop.pdf. [Last cited on 2015 Sep 09].

18. Dauqan EM, Sani HA, Abdullah A, Kasim ZM. Fatty acids composition of four different vegetable oils (red palm olein, palm olein, corn oil and coconut oil) by gas chromatography. In: The $2^{\text {nd }}$ International Conference on Chemistry and Chemical Engineering, IPCBEE. Singapore: IAGSIT Press; 2014.

19. Hamaguchi M, Kojima T, Itoh Y, Harano Y, Fuji K, Nakajima T, et al. The severity of ultra-sonographic findings in non-alcoholic fatty liver disease reflects the metabolic syndrome and visceral fat accumulation. Am J Gastroenterol 2007;102:2708-15.

20. Festi D, Schiumerini R, Marzi L, Di Biase AR, Mandolesi D, Montrone L, et al. Review article: The diagnosis of non-alcoholic 
fatty liver disease-availability and accuracy of noninvasive methods. Aliment Pharmacol Ther 2013;37:392-400.

21. Kirkwood BR, Sterne JA. Essential Medical Statistic. $2^{\text {nd }}$ ed. Singapore: Blackwell Science; 2003.

22. Yang LG, Song ZX, Yin H, Wang YY, Shu GF, Lu HX, et al. Low n-6/n-3 PUFA ratio improves lipid metabolism, inflammation, oxidative stress and endothelial function in rats using plant oils as n-3 fatty acid source. Lipids 2016;51(1):49-59.

23. Heerwagen MJ, Stewart MS, de la Houssaye BA, Janssen RC, Friedman JE. Transgenic increase in N-3/n-6 fatty acid ratio reduces maternal obesity-associated inflammation and limits adverse developmental programming in mice. PLoS One 2013;8(6):e67791.

24. Depner CM, Philbrick KA, Jump DB. Docosahexaenoic acid attenuates hepatic inflammation, oxidative stress, and fibrosis without decreasing hepatosteatosis in a Ldlr2/2 mouse model of western diet-induced nonalcoholic steatohepatitis. J Nutr 2013;143:315-23.

25. Lionetti L, Mollica MP, Sica R, Donizzetti I, Gifuni G, Pignalosa A, et al. Differential effects of high-fish oil and high-lard diets on cells and cytokines involved in the inflammatory process in rat insulin-sensitive tissues. Int J Mol Sci 2014;15(2):3040-63.

26. Parker HM, Johnson NA, Burdon CA, Cohn JS, O’Connor HT, George J. Omega-3 supplementation and non-alcoholic fatty liver disease: A systematic review and meta-analysis. J Hepatol 2012;56(4):944-51.

27. Ruzickova J, Rossmeisl M, Prazak T, Flachs P, Sponarova J, Veck M, et al. Omega-3 PUFA of marine origin limit diet-induced obesity in mice by reducing cellularity of adipose tissue. Lipids 2004;39(12):1177-85.

28. Nobili V, Bedogni G, Alisi A, Pietrobattista A, Risé P, Galli C, et al. Docosahexaenoic acid supplementation decreases liver fat content in children with non-alcoholic fatty liver disease: Double-blind randomised controlled clinical trial. Arch Dis Child 2011;96(4):350-3.

29. Nobili V, Alisi A, Della Corte C, Risé P, Galli C, Agostoni C, et al. Docosahexaenoic acid for the treatment of fatty liver: Randomised controlled trial in children. Nutr Metab Cardiovasc Dis 2013;23(11):1066-70.

30. Sanders TA, Lewis F, Slaughter S, Griffin BA, Griffin M, Davies I, et al. Effect of varying the ratio of n-6 to n-3 fatty acids by increasing the dietary intake of alpha-linolenic acid, eicosapentaenoic and docosahexaenoic acid, or both on fibrinogen and clotting factors VII and XII in persons aged 45-70 y: The OPTILIP study. Am J Clin Nutr 2006;84(3):513-22.

31. Chavarro JE, Stampfer MJ, Li H, Campos H, Kurth T, Ma J.A prospective study of polyunsaturated fatty acid levels in blood and prostate cancer risk. Cancer Epidemiol Biomarkers Prev 2007;16(7):1364-70.

32. Wu CC, Huang MY, Kapoor R, Chen CH, Huang YS. Metabolism of omega- 6 polyunsaturated fatty acids in women with dysmenorrhea.
Asia Pac J Clin Nutr 2008;17 Suppl 1:216-9.

33. Wang X, Lin H, Gu Y. Multiple roles of dihomo-?-linolenic acid against proliferation diseases. Lipids Health Dis 2012;11:25.

34. Burdge GC, Wootton SA. Convertion of alpha linolenic acid to ecosapentanoic, docosapenta-enoic and docosa-hexanoic acids in young women. Br J Nutr 2002;88:411-20.

35. Mejía-Barradas CM, Del-Río-Navarro BE, Domínguez-López A, Campos-Rodríguez R, Martínez-Godínez MD, Rojas-Hernández S, et al. The consumption of n-3 polyunsaturated fatty acids differentially modulates gene expression of peroxisome proliferator-activated receptor alpha and gamma and hypoxia-inducible factor 1 alpha in subcutaneous adipose tissue of obese adolescents. Endocrine 2014;45(1):98-105.

36. Wójcik C, Lohe K, Kuang C, Xiao Y, Jouni Z, Poels E. Modulation of adipocyte differentiation by omega-3 polyunsaturated fatty acids involves the ubiquitin-proteasome system. J Cell Mol Med 2014;18(4):590-9.

37. Yahagi N, Shimano H, Hasty AH, Amemiya-Kudo M, Okazaki H, Tamura $\mathrm{Y}$, et al. A crucial role of sterol regulatory elementbinding protein-1 in the regulation of lipogenic gene expression by polyunsaturated fatty acids. J Biol Chem 1999;274(50):35840-4

38. Xu J, Nakamura MT, Cho HP, Clarke SD. Sterol regulatory element binding protein-1 expression is suppressed by dietary polyunsaturated fatty acids. A mechanism for the coordinate suppression of lipogenic genes by polyunsaturated fats. J Biol Chem 1999;274(33):23577-83.

39. Koenig G, Seneff S. Gamma-glutamyltransferase: A predictive biomarker of cellular antioxidant inadequacy and disease risk. Dis Markers 2015;2015:818570.

40. Konuma K, Itoh M, Suganami T, Kanai S, Nakagawa N, Sakai T, et al. Eicosapentaenoic acid ameliorates non-alcoholic steatohepatitis in a novel mouse model using melanocortin 4 receptor-deficient mice. PLoS One 2015;10(3):e0121528.

41. Abdel-Sttar AR, Khalaf MM, Aboyoussef AM, Abosaif AA. Ameliorative effect of hesperidin on carbon tetrachloride induced liver fibrosis in rats. Int J Pharm Pharm Sci 2017;9(7):45-51.

42. Ahmed AH, Salem AM, Mohamed MR, Shahat AA, Khalil WK, Mohamed SH. Experimental evidences for the promising therapeutic role of Vitis vinifera seed extract against nonalcoholic steatohepatitis. Int J Pharm Pharm Sci 2015;7(2):417-24.

43. Di Minno MN, Russolillo A, Lupoli R, Ambrosino P, Di Minno A, Tarantino G. Omega-3 fatty acids for the treatment of non-alcoholic fatty liver disease. World J Gastroenterol 2012;18(41):5839-47.

44. Devaraj S, Hemarajata P, Versalovic J. The human gut microbiome and body metabolism: Implications for obesity and diabetes. Clin Chem 2013;59(4):617-28. 